\title{
PROFIL LIPID PADA PASIEN DENGAN PENYAKIT JANTUNG KORONER DI BLU RSUP PROF. DR. R. D. KANDOU TAHUN 2012
}

\author{
${ }^{1}$ Jian A. Lee \\ ${ }^{2}$ Linda Rotty \\ ${ }^{2}$ Frans E. Wantania
}

\author{
${ }^{1}$ Kandidat Skripsi Fakultas Kedokteran Universitas Sam Ratulangi Manado \\ ${ }^{2}$ Bagian Ilmu Penyakit Dalam Fakultas Kedokteran Universitas Sam Ratulangi Manado \\ Email: Jian.Alberto@yahoo.co.id
}

\begin{abstract}
Diabetes mellitus (DM) is a health problem that increases the number of events globally. Medical doctor as the first line in the treatment of diabetes are required to have good knowledge about its management. Students of the Faculty of Medicine, University of Sam Ratulangi trained to become medical doctor were had good knowledge about management of diabetes melitus. The problem is what is the description of knowledge about DM management on undergraduate students and professional education programs of medical doctor (P3D) students. This study aimed to compare the level of knowledge about DM management among undergraduate students and P3D students of Faculty of Medicine, University of Sam Ratulangi. This was a descriptive analytical study with a quantitative approach involving 80 subjects were selected based consecutive sampling and was answered the questionnaire about knowledge of DM management. Results: The subjects knowledge about DM management in undergraduate students from 40 subject result 1 subject $(2.5 \%)$ are included in the category of good knowledge, 7 subject $(17.5 \%)$ had moderate knowledge and 32 subjects (80\%) are included of low knowledge. From the P3D students, 3 subjects (7.5\%) with good knowledge category, 25 subjects (62.5\%) with moderate knowledge and 12 subjects (30\%) with low knowledge category. Conclusion: Knowledge level about DM management among undergraduate students was still low. P3D student knowledge level about diabetes management was classified as moderate. Knowledge level about diabetes management among P3D students was better than undergraduate students.
\end{abstract}

Keywords: Knowledge, medical students, management of diabetes mellitus

\begin{abstract}
Abstrak: Penyakit Jantung Koroner merupakan salah satu bentuk dari penyakit kardiovaskuler (penyakit jantung dan pembuluh darah) yang menjadi penyebab kematian nomor satu di dunia. Penyebab PJK secara pasti belum diketahui, meskipun demikian secara umum dikenal berbagai faktor yang berperan penting terhadap timbulnya PJK yang disebut sebagai faktor risiko PJK seperti Dislipidemia , Hipertensi , dan obesitas. Penelitian ini bertujuan untuk Mencari tahu Peran penting Peningkatan profil Lipid pada pasien Penyakit Jantung Koroner di BLU RSUP Prof Kandou tahun 2012. Penelitian yang digunakan adalah penelitian yang bersifat deskriptif dan dilaksanakan dengan cara mengambil / mengumpulkan data sekunder rekam medis sebanyak 32 sampel di Bagian Ilmu Penyakit Dalam sub.bagian kardiovaskuler RSUP Prof. DR. R. D. Kandou Manado. Dari 32 sampel pasien Penyakit jantung koroner Manado81\%(26 orang) dengan kolestrol total yang di inginkan , 91\%(29 orang) dengan LDL rendah , 69\%(22 orang) dengan trigliserida yang di inginkan , dan 47\%(16 orang) dengan LDL batas normal tertinggi. Simpulan: Profil lipid sangat berperan penting dalam proses terjadinya penyakit jantung koroner terutama pada peningkatan LDL dan penurunan HDL
\end{abstract}

Kata kunci: pengetahuan, mahasiswa kedokteran, manajemen diabetes mellitus

Kemajuan perekonomian sebagai dampak dari pembangunan di negara-negara sedang berkembang sebagai-mana di Indonesia menyebabkan perbaikan tingkat hidup. Hal 
ini menjadikan kesehatan masyarakat meningkat, di samping itu terjadi pula perubahan pola hidup. Perubahan pola hidup ini yang menyebabkan pola penyakit berubah, dari penyakit infeksi dan rawan gizi ke penyakit-penyakit degeneratif, diantaranya adalah penyakit jantung dan pembuluh darah (kardiovaskuler) dan akibat kematian yang ditimbulkannya. Hasil Riset Kesehatan Dasar 2013 didapatkan prevalensi jantung koroner berdasarkan wawancara terdiagnosis dokter di Indonesia sebesar 0,5 persen, dan berdasarkan terdiagnosis dokter atau gejala sebesar 1,5 persen. Prevalensi jantung koroner berdasarkan terdiagnosis dokter tertinggi Sulawesi Tengah $(0,8 \%)$ diikuti Sulawesi Utara, DKI Jakarta, Aceh masingmasing 0,7 persen. Sementara prevalensi jantung koroner menurut diagnosis atau gejala tertinggi di Nusa Tenggara Timur (4,4\%), diikuti Sulawesi Tengah (3,8\%), Sulawesi Selatan (2,9\%), dan Sulawesi Barat $(2,6 \%){ }^{1}$

Perubahan tersebut telah memberi pengaruh terhadap terjadinya transisi epidemiologi dengan semakin meningkatnya Penyakit Tidak Menular (PTM) seperti Penyakit Jantung Koroner (PJK), Stroke, Hipertensi, dan Kanker. ${ }^{2}$

Penyakit Jantung Koroner merupakan salah satu bentuk dari penyakit kardiovaskuler (penyakit jantung dan pembuluh darah) yang menjadi penyebab kematian nomor satu di dunia. ${ }^{2}$

Pada tahun 2005 sedikitnya 17,5 juta atau setara dengan 30,0 \% kematiandiseluruh dunia disebabkan oleh penyakit jantung. Menurut Badan Kesehatan Dunia (WHO), 60\% dari seluruh penyebab kematian penyakit jantung adalah penyakit jantung koroner (PJK). ${ }^{3}$

Menurut laporan WHO 2001, jumlah penderita penyakit kardiovaskuler tahun 2000 mencapai 151 juta dan mengakibatkan 16,7 juta kematian (Case Fatality Rateakibat kardiovaskuler sebesar 11,06\%), dengan rincian penderita PJK 55,7 juta (36,9\%), stroke 45,7 juta (30,3\%), radang jantung 6,6 juta $(4,4 \%)$, penyakit jantung rematik 6,5 juta (4,3\%), penyakit jantung lainnya 36,5 juta akibat PJK 6,9 juta (41,3\%), akibat stroke 5,1 juta (30,5\%), akibat radang jantung 400 ribu $(2,4 \%)$, akibat penyakit jantung rematik 300 ribu (1,8\%), penyakit jantung lainnya 4 juta (24\%). Ini berarti Case Fatality Rate akibat Penyakit Jantung Koroner sebesar 12,38\%. Penyebab PJK secara pasti belum diketahui, meskipun demikian secara umum dikenal berbagai faktor yang berperan penting terhadap timbulnya PJK yang disebut sebagai faktor risiko PJK.

Berdasarkan penelitian-penelitian epidemiologis prospektif, misalnya penelitian Framingham, Multiple Risk Factors Interventions Trial dan Minister Heart Study (PROCAM), diketahui bahwa faktor risiko seseorang untuk menderita PJK ditentukan melalui interaksi dua atau lebih faktor risiko. ${ }^{3,4}$

Faktor-faktor yang memicu seseorang menderita PJK Antara lain:

1. Faktor yang tidak dapat dikendalikan: Keturunan, Umur (makin tua risiko makin besar), Jenis kelamin (pria mempunyai risiko lebih tinggi dari pada wanita (wanita risikonya meningkat sesudah menopouse). ${ }^{5}$

2. Faktor yang dapat dikendalikan: Dislipidemia, Tekanan darah tinggi (hipertensi), Merokok, Penyakit Diabates Mellitus, Stres, Kelebihan berat badan dan obesitas. ${ }^{6}$

\section{METODE PENELITIAN}

Penelitian yang digunakan adalah penelitian yang bersifat deskriptif dan dilaksanakan dengan cara mengambil / mengumpulkan data sekunder rekam medis di Bagian Ilmu Penyakit Dalam sub.bagian kardiovaskuler RSUP Prof. DR. R. D. Kandou Manado. Penelitian dilakukan dengan mengambil data sekuder di BLU RSUP Prof. DR. R. D. Kandou Manado . waktu penelitian Januari-Desember 2012. Populasi adalah seluruh penderita penjakit Jantung di Bagian Ilmu Penyakit Dalam sub.bagian kardiovaskuler RSUP. Prof. Dr. R.D. Kandou Manado tahun 2012. penulis melakukan observasi, dan pengamatan di Bagian Ilmu Penyakit Dalam sub.bagian 
kardiovaskuler, setelah itu melakukan pengambilan data dan pencatatan data pasien di Bagian Ilmu Penyakit Dalam sub.bagian kardiovaskuler, dan mengolah data yang di dapat.

\section{HASIL PENELITIAN}

Pada penelitian yang dilakukan didapatkan hasil dari data rekam medik dengan jumlah penderita penyakit koroner sebanyak 32 orang . ditemukan sebanyak 5 orang yang menderita infark miokard akut, 4 orang menderita penyakit jantung iskemik kronik, 23 orang menderita penyakit infark miokard kronik. Dari 32 pasien di dapatkan 19 orang laki-laki dan 13 orang pasien perempuan. Melalui data ini juga di dapatkan 1 orang pasien dengan umur $<30$ tahun, 3 orang pasien dengan umur 30-40 tahun, 7 orang pasien dengan umur 40-50tahun, 11 orang pasien dengan umur 50-60tahun, 9 orang pasien dengan umur $60-70$, dan 1 orang pasien $>70$ tahun.

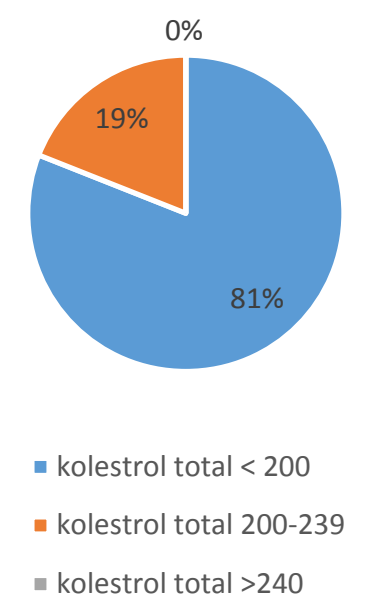

Gambar 1. Kadar Kolestrol Total pada Penyakit Jantung koroner

Dari data di atas di temukan bahwa dari 32 data penderita penyakit jantung koroner, di temukan 26 (81\%) orang dengan kolestrol total $<200$, kadar kolestrol ini yang di inginkan kepada pasien agar dapat menurunkan resiko PJK , di temukan juga $6(19 \%)$ orang dengan kolestrol total 200-239, ini merupakan batas tinggi penderita, dan tidak ditemukan pasien dengan kolestrol total >240 (Gambar 1).

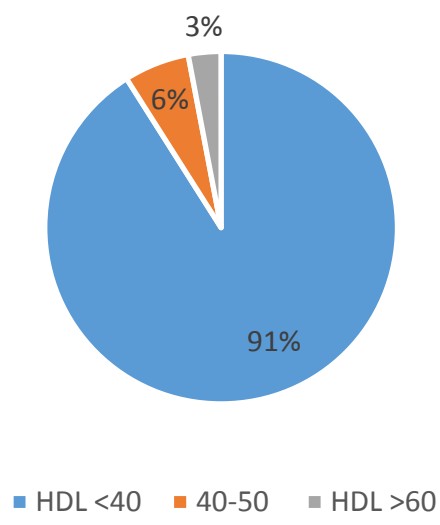

Gambar 2. Kadar HDL pada penyakit jantung koroner

Data yang di peroleh dari 32 orang di temukan, 29 (91\%) orang dengan HDL $<40,2$ (6\%) orang dengan kadar HDL 4060 dan 1 (3\%) orang dengan HDL <60, pada orang normal kadar HDL yang tinggi dapat menurunkan kadar resiko terkena penyakit jantung koroner (Gambar 2).

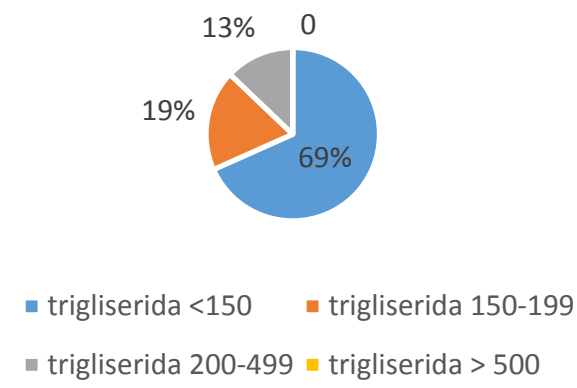

Gambar 3. Kadar Trigliserida pada jantung koroner

Diperoleh dari data rekam medik 22 (69\%) orang memiliki kadar trigliserida $<150,6$ (19\%) orang kadar trigliserida 150199, 4 (13\%) orang kadar trigliserida 200499, dan tidak ada pasien untuk kadar trigliserida $>500$ (Gambar 3).

Dari data di temukan 9 orang (31\%) orang pasien dengan kadar LDL $<100,5$ orang (16\%) orang dengan kadar LDL 100-129, 16orang (47\%) orang dengan kadar LDL 130-159, 2 orang (6\%) orang dengan kadar LDL 160-189, dan tidak di 
temukan pasien dengan kadar LDL > 190 (Gambar 4).

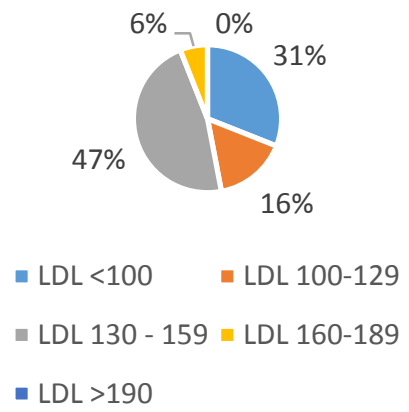

Gambar 4. Kadar LDL pada penyakit jantung koroner

\section{BAHASAN}

Dislipidemia diyakini sebagai faktor risiko mayor yang dapat dimodifikasi untuk perkembangan dan perubahan secara progresif atas terjadinya PJK. Kolesterol ditranspor dalam darah dalambentuk lipoprotein, $75 \%$ merupakan lipoprotein densitas rendah (lowdensity liproprotein/LDL) dan 20 \% merupakan lipoprotein densitas tinggi (highdensity liproprotein/HDL). Kadar kolesterol HDLlah yang rendah memiliki peran yang baik pada PJK dan terdapat hubungan terbalik antara kadar HDL dan insiden PJK. ${ }^{23}$

Berdasarkan studi epidemiologis didapatkan bahwa penurunana kadar kolesterol total sebanyak 1\% akan menurunkan angka kejadian PJK sebanyak 2-3\% (NCEP-ATP III, 2001;Ginsberg HN \& Goldberg IJ,2001).

Trigliserida adalah tipe lemak lain dalam darah.Level TG yang tinggi umumnya menunjukkan bahwa anda makan lebih banyak kalori daripada kalori yang dibakar untuk aktivitas, karena itu level TG biasanya tinggi pada pasien yang gemuk atau pasien diabetes. ${ }^{21}$

Peranan trigliserida sebagai faktor risiko PJK masih controversial. Kadar trigliserida yang meningkat banyak dikaitkan dengan pankreatitis dan harus diterapi. Hiperlipidemia gabungan (misalnya pada diabetes) membutuhkan intervensi, namun kekuatan trigliserida sebagai satu faktor risiko jika kolesterol kembali normal adalah lemah.

Idealnya level trigliserida haruslah $<150 \mathrm{mg} / \mathrm{dL}$ (1.7 mmol/L). American Heart Association (AHA) merekomendasikan bahwa level TG untuk kesehatan jantung "optimal” adalah 100 mg/dL (1.1 $\mathrm{mmol} / \mathrm{L})^{21}$

Diketahui bahwa LDL dapat masuk menembus endotel pembuluh darah nadi dan kemudian mengalami perubahan dan akhirnya menunjukan ditangkap oleh sel makrofag dan membentuk sel busa. ${ }^{22}$

HDL mengangkut kolesterol dari sel kembali ke hati (jalur angkut baik kolestrol = reverse cholesterol transport), mencagah pembentukan sel busa , menghabat molekul adhesi yang memungkinkan monosit masuk ke bawah sel endotel dinding arteri , menghambat perubahan oksidatif oleh LDL. ${ }^{22}$

\section{SIMPULAN}

Yang dapat ditemukan dari penderita Penyakit jantung koroner yang datang ke Bagian Ilmu Penyakit Dalam sub.bagian kardiovaskuler Prof. DR. R. D. Kandou Manado adalah 81\%(26 orang) dengan kolestrol total yang di inginkan , 91\%(29 orang) dengan LDL rendah , 69\%(22 orang) dengan trigliserida yang di inginkan , dan 47\%(16 orang) dengan LDL batas normal tertinggi, jadi yang sangat berpengaruh adalah peningkatan LDL dan penurunan HDL yang signifikan .

\section{DAFTAR PUSTAKA}

1. Susiana C, Lantip R, Thianti S. Kadar malondiadehid (MDA) penderita penyakit jantung koroner di RSUP Dr. Sardjito Yogyakarta, Mandala of Health, a Scientific Journal, Vol 2, 2006, 47-54.

2. Bustan MN. 2000. Epidemiologi Penyakit Tidak Menular. Rineka Cipta, Jakarta.

3. WHO, WHO World Health Organization Report 2000, Genewa: WHO, 2001.

4. Soeharto. Penyakit jantung koroner dan serangan jantung, PT. Gramedia Pustaka Utama, Jakarta, 2004.

5. Brian HG, Michael HD. Cardiovascular disease : practical applications of the 
NCEP ATP III Update, Patient Care The Jurnal of Best Clinical Practices for Today’s Physicians, March 2005, 1-4.

6. De Bacquer MD, De Backer G, Amouye P. Overweight and obesity: a major challenge for coronary heart disease secondary prevention in clinical practice in Europe, European Heart Journal, 2000, 808-813.

7. Krisnatuti D, Yehrina R. 1999. Perencanaan menu bagi penderita penyakit Jantung koroner. Penerbit PT. Trumbus Agriwidya, Jakarta

8. WHO, Conquering Suffering, Enriching Humanity, WHO Geneva, 1997.

9. Soeharto I. 2004. Serangan Jantungdan Stroke. Penebit PT. Gramedia Pustaka Utama, Jakarta.

10. Rilantono IL, et al. 1998. Buku Ajar Kardiologi. Penerbit FKUI. Jakarta.

11. D'Angelo R, et al., 2007. The Ultimate Guide to Heart Attack Treatment. Penerbit Prestasi Pustakaraya, Jakarta.

12. Grey HH, et al. 2003. Lecture Notes Kardiologi. Penerbit Erlangga, Jakarta.

13. Soewono BS. 2003. Ilmu Penyakit Jantung. Penerbit Airlangga University Press, Surabaya. Laurence, M, dkk., 2002.

14. Diagnosis dan Terapi Kedokteran Ilmu
Penyakit Dalam. Salemba Medika, Jakarta.

15. Bustan MN. 2002. Pengantar Epidemiologi. Penerbit Rineka Cipta, Jakarta.

16. Mc Gowan MP, et al. 2001. Menjaga Kebugaran Jantung. Penerbit PT. Rajagrafindo Persada, Jakarta

17. Tara E, Soetrisno E. 2003. Buku Pintar Terapi Alami Jantung. Penerbit Intimedia Ladang Pustaka, Jakarta.

18.Irawan M, et al. 1998. Waspadai Ancaman Stroke dan Jantung Koroner Penerbit Carya Remaja, Bandung

19. Yatim F. 2000.Waspadai Jantung Koroner Stroke Meninggal Mendadak Atasi dengan Pola Hidup Sehat. Penerbit Pustaka Populer Obor, Jakarta

20. Davidson C. 2003. Penyakit Jantung Koroner. Penerbit Dian Rakyat, Jakarta.

21. Morrow DA, et al. Chronic coronary artery disease. In: Libby $\mathrm{P}$, et al., eds. Braunwald's Heart Disease: A Textbook of Cardiovascular Medicine. 8th ed. Philadelphia, Pa.: Saunders Elsevier; 2007.

22. Michael B, Clearfield, DO. The national cholesterol education program adult treatment panel III guidelines, JAOA, Supplement I Vol 103 No. 1, January, 2003, 51-55. 